\title{
SPEECH STRATEGY OF COMMUNICATIVE INITIATIVE CONTROL (ON MATERIAL OF GERMAN TALK-SHOW ABOUT HEALTH)
}

\author{
Elena Yu. Vasil'eva \\ Volgograd State University, Volgograd, Russia
}

\begin{abstract}
In the article mechanisms of the speech strategy of a communicative initiative control in a media medical discourse are described from a position of pragmalinguistics. Releases of the German talk-show about health "Hauptsache Gesund" served as material for the research. It is presumed that voluntary efforts to regulate exchange of communicative roles might influence the speech strategy of a communicative initiative control by means of different tactics in relation to the status of communicants. In the course of the research the following speech tactics were revealed: tactics of "an initiative transfer", of "taking of an initiative", of "stimulation of an initiative", of "evasion from an initiative" and "conclusion of a conversation". By means of correlation between communicative efforts of speech interaction partners the leading role of the moderator (a host of the talk show) in the course of redistribution of a communicative initiative is verified. It is revealed that the most frequent tactics are: tactics of "an initiative transfer" which is carried out by actions of the talk-show host with the aim to contribute to the development of subject lines of the program and to prepare mass audience for discussion of a new subject; the tactics of "conclusion of a conversation", implemented by means of a subject change and switching attention onto other speaker.
\end{abstract}

Key words: medical discourse, medical media discourse, speech strategy, speech tactics, control of the communicative initiative, exchange of communicative roles, verbal signal, non-verbal signal.

Citation. Vasil'eva E.Ju. Speech Strategy of Communicative Initiative Control (On Material of German TalkShow about Health). Vestnik Volgogradskogo gosudarstvennogo universiteta. Seriya 2. Yazykoznanie [Science Journal of Volgograd State University. Linguistics], 2019, vol. 18, no. 2, pp. 183-194. (in Russian). DOI: https:// doi.org/10.15688/jvolsu2.2019.2.16

\section{РЕЧЕВАЯ СТРАТЕГИЯ КОНТРОЛЯ КОММУНИКАТИВНОЙ ИНИЦИАТИВЫ (НА МАТЕРИАЛЕ НЕМЕЦКОГО ТОК-ШОУ О ЗДОРОВЬЕ)}

\author{
Елена Юрьевна Васильева \\ Волгоградский государственный университет, г. Волгоград, Россия
}

\begin{abstract}
Аннотация. В статье с позиций прагматической лингвистики описываются механизмы реализации речевой стратегии контроля коммуникативной инициативы в пространстве медицинского медийного дискурca. Материалом для исследования послужили выпуски немецкого ток-шоу о здоровье «Наuptsache Gesund» (2015-2018 гг.). Показано, что целенаправленные усилия по контролю мены коммуникативных ролей составляют речевую стратегию контроля коммуникативной инициативы, которая реализуется с помощью разных . тактик в зависимости от статуса коммуникантов: «передачи инициативы», «взятия инициативы», «поощрения инициативы», «уклонения от инициативы» и «завершения разговора». Посредством соотнесения коммуникативных усилий партнеров речевого взаимодействия установлено, что значимой в процессе перераспределения коммуникативной инициативы является роль модератора (ведущего ток-шоу). Определены наиболее частотные тактики: тактика «передачи инициативы», которая реализуется действиями ведущего токшоу, поскольку его основная задача - способствовать развитию сюжетных линий программы и подготавливать массовую зрительскую аудиторию к обсуждению новой темы, и тактика «завершения разговора», кото-
\end{abstract}


рая реализуется сменой темы и переключением внимания на другого собеседника. Показано, что при воплощении стратегии контроля коммуникативной инициативы участниками ток-шоу применяются и невербальные сигналы, сопровождающие высказывание и актуализирующие ту или иную тактику.

Ключевые слова: медицинский дискурс, медицинский медийный дискурс, речевая стратегия, речевая тактика, контроль коммуникативной инициативы, мена коммуникативных ролей, вербальный сигнал, невербальный сигнал.

Цитирование. Васильева Е. Ю. Речевая стратегия контроля коммуникативной инициативы (на материале немецкого ток-шоу о здоровье) // Вестник Волгоградского государственного университета. Серия 2 , Языкознание. -2019. - Т. 18, № 2. - C. 183-194. - DOI: https://doi.org/10.15688/jvolsu2.2019.2.16

\section{Введение}

В современном медицинском медийном дискурсе, как и в других видах дискурса, коммуникация осуществляется в вербальной форме. Участвуя в коммуникации, говорящий имеет своей целью донести до слушающего необходимую информацию и достичь, таким образом, правильного толкования им своего намерения. Следовательно, адресант должен организовать свое речевое поведение так, чтобы оно адекватно воспринималось адресатом. Для достижения целей речевого общения коммуниканты применяют специальные коммуникативные стратегии и тактики. Как подчеркивает М.Л. Макаров, термины «коммуникативная стратегия» и «коммуникативная тактика» используются в любых более или менее серьезных трудах по коммуникативной лингвистике [Макаров, 2003, с. 193]. Разработкой проблем коммуникативных стратегий и тактик занимаются многие лингвисты (см., например: [Дейк, Кинч, 1988; Демьянков, 1983; Ильина, Покидов, 2017; Иссерс, 2008; Лукашова, 2014; Невзорова, 2017; Петрова, Егорченкова, Шамне, 2016; Сухих, 1986; Parret, 1983]), однако до сих пор нет их единой классификации. Это объясняется различными причинами: большим количеством жизненных ситуаций, разнообразием психотипов адресантов, форм коммуникации (монолог или диалог; устная или письменная).

Одним из первых отечественных лингвистов, использовавших в своих трудах понятия стратегии и тактики, является В.3. Демьянков. Исследователь считает, что сущность стратегий заключается в соблюдении определенных правил общения, и выделяет два типа стратегических планов, реализуемых адресантом: осознанный и подсознательный. Выполнение коммуникантом стратеги- ческого плана осуществляется посредством нескольких тактик, зачастую одной основной и нескольких второстепенных [Демьянков, 1983, с. 122]. Многие ученые рассматривают стратегию в качестве умения планировать и организовывать общение таким образом, чтобы достичь желаемой коммуникативной цели. Тактику определяют как целенаправленный выбор языковых средств, способных повлиять на коммуниканта, как общность речевых действий, которая направлена на достижение цели коммуникации [Ильина, Покидов, 2017, с. 69].

Понимание стратегий и тактик как целенаправленной деятельности носителей языка закрепилось в учебной литературе (см., например: [Клюев, 2002, с. 7]). Автор этого пособия характеризует и механизм выбора той или иной стратегии: «Используя коммуникативную компетенцию, говорящий ставит перед собой коммуникативную цель и, следуя определенной коммуникативной интенции, вырабатывает коммуникативную стратегию» [Клюев, 2002, с. 12]. Для достижения цели необходимым условием является рациональный выбор и использование тактик, которые трактуются как «совокупность практических ходов в реальном процессе речевого взаимодействия» [Клюев, 2002, с. 19]. Таким образом, основные характерные черты коммуникативных стратегий и тактик сформированы на основе целевой направленности индивида.

Кроме понятий коммуникативных стратегии и тактики для нашего исследования значимо понятие диалога. С технической точки зрения диалог выступает одним из основных объектов изучения в науке о языке [Арутюнова, 1990; Sacks, 1992]. Это обусловлено тем, что, несмотря на появление новых коммуникационных приемов, средств и методов, систематическая человеческая коммуникация представ- 
ляет собой тесное диалогическое взаимоотношение, иными словами разговор. Поскольку диалог характеризуется динамичным сотрудничеством участников коммуникации, он развивается посредством мены коммуникативных ролей - адресанта и адресата. В диалоге вероятно неравенство речевых позиций говорящего и слушающего, вследствие чего в лингвистике появился термин «коммуникативная инициатива». М.Л. Макаров дает следующее его определение: «Коммуникативная инициатива - это процесс взаимовлияния стратегий, при котором ходы одного из коммуникантов определяют и предписывают пути развития дискурса» [Макаров, 2003, с. 217].

В исследованиях характеризуются случаи, когда обычная поочередная мена ролей адресанта и адресата нарушается участниками речевого взаимодействия. Коммуникативную инициативу можно перехватить или принудительно передать партнеру, следовательно, необходимо отличать инициативу адресанта и адресата в процессе мены коммуникативных ролей. Коммуникативная роль адресанта может перейти к адресату посредством следующих действий: адресантом становятся в результате обращения; от адресата требуется ответ на вопрос; очередного адресанта назначают партнеры речевого взаимодействия. Однако на обмен репликами может повлиять способ захвата инициативы адресатом. Мена коммуникативных ролей может быть реализована: по «гладкому» сценарию; в случае перебивания партнера; после паузы (подробно о таких ситуациях см.: [Макаров, 2003, с. 191; Яшина, 2014, с. 215]).

Согласно концепции О.С. Иссерс, перераспределение инициативы в диалоге связано со специальными действиями участников коммуникации, вызывающими нарушение процесса естественной мены ролей. Данные действия выражаются в тех или иных фразах, которые или содействуют сохранению инициативы говорящего, или же способствуют переходу инициативы от одного участника речевого взаимодействия к другому. Такое воздействие на процесс диалога осуществляется посредством речевой стратегии контроля инициативы. Исследователь систематизирует тактики, которые способствуют реализации этой стратегии, учитывая следу- ющие параметры: переход или удержание инициативы адресантом; принудительный или добровольный характер передачи инициативы; усилия партнеров в отношении передачи инициативы, включающие такие тактики, как «перераспределение инициативы», «сохранение инициативы», «завершение разговора» [Иссерс, 2008, с. 215].

Управление инициативой представляет собой основной показатель владения коммуникативной инициативой. Он ярко выражен в таких типах институционального дискурса, как судебный, учебный, медийный. В данных типах дискурса возможность передавать инициативу имеет тот участник коммуникации, который изначально является более значимой коммуникативной фигурой (судья, учитель, ведущий) [Кудрявцева, 2017, с. 44].

В центре нашего внимания находится медицинский медийный дискурс. Материалом для анализа послужили видеозаписи немецкого телевизионного ток-шоу «Hauptsache Gesund», посвященного медицине и проблемам со здоровьем, - 10 выпусков ток-шоу с 2017 по 2018 г. общей продолжительностью звучания 8 часов ${ }^{1}$.

\section{Результаты и обсуждение}

Стратегия контроля коммуникативной инициативы реализуется в диалогах участников ток-шоу речевыми тактиками «передачи инициативы», «взятия инициативы», «поощрения инициативы», «уклонения от инициативы», «завершения разговора». Тактика «передачи инициативы» реализуется посредством прямого обращения, называющего следующего говорящего по имени:

(1) Ситуативный контекст: К.1 - ведущий, К.2эксперт.

K.1: Nicole, die Grundzutaten für Bier, also Wasser, Hopfen und Malz, die kennt fast jeder. Aber was am Ende im Glas ist, das ist vielleicht für manchen überraschend.

K.2: Man muss immer auf die Menge aufpassen. Alkohol ist ja nicht immer gut für die Leber (29.11.2018).

Обращения могут свидетельствовать как о дистанции между собеседниками (вежливое официальное обращение на «Вы»), так и о ее сокращении (обращение на «ты», которое яв- 


\section{МАТЕРИАЛЫ И СООБЩЕНИЯ}

ляется показателем того, что коммуниканты, скорее всего, знакомы друг с другом):

(2) Ситуативный контекст: К.1 - ведущий, К. 2 - врач.

K.1: Für welche Patienten kommt so eineOperation mit einem Ballon infrage? Erzählen Sie uns bitte!

K.2: Insbesondere dann, wenn Rekonstruktionen der Sehne nicht mehr möglich sind (29.11.2018).

(3) Ситуативный контекст: К.1 - эксперт токшоу, К.2 - спортсмен.

K. 1: Sag mal Franz, sag mal, hast du es nach so einem Training schon mal mit einem alkoholfreies Bier getrunken, zur Erfrischung?

K.2: Nein, noch nie (20.04.2017).

При реализации тактики «передачи инициативы» адресант претендует на роль адресата, поэтому, формулируя вопрос по интересующей теме, дает возможность слушающему высказаться по той или иной проблеме:

(4) Ситуативный контекст: К.1 - ведущий, К. 2 - врач.

K. 1: Man denkt ja immer, Beschwerden mit der Achillessehne haben nur junge Sportler. Aber das ist gar nicht so! Warum sind auch Ältere so anfällig dafür?

K.2: Es trifft vor allem ältere Leute. DiegrössteGruppe sind Männer ab 50. Das etwas mit der Hormonumstellung zu tun. Da lagern sich freie Radikale in den grossen Sehnen ab. Das Gewebe wird belastungunfähiger und reist dadurch schneller (01.06.2017).

В примере (4) тактика «передачи инициативы» реализуется не только посредством специального вопроса (Warum sind auch Ältere so anfällig dafür?), но и благодаря невербальным сигналам - знакам, имеющим материальную (действия и движения человека) и идеальную (значение, смысл, отражающие психологическое состояние той или иной личности) составляющие. Жесты могут сообщать дополнительную информацию, замещать отсутствующий вербальный элемент, дублировать смысл, который передается вербально (подробно об этом см.: [Петрова, Егорченкова, Шамне, 2016, с. 91]). В примере (4) таким невербальным сигналом является прямой взгляд адресанта на собеседника. Посредством такого знака адресант приглашает собеседника взять слово (рис. 1).

В исследуемом материале тактика «передачи инициативы» реализуется с помощью фраз и наречий, выражающих уточнение: Das heist also..., also..., beziehungsweise..., wie ich verstanden habe... Их функция состоит в том, чтобы восстановить опущенную информацию, перепроверить сказанное или выяснить личное представление партнера о какой-то проблеме:

(5) Ситуативный контекст: К.1 - ведущий, К. 2 - врач.

K.1: Das heist also, dass, was ich rausschwitze, das kommt auch idealerweise ganz schnell wieder hinein.

K.2: Genau, je ähnlicher dieses Konstrukt, desto schneller kann der Körper die Mineralien als auch das Wasser aufnehmen (29.11.2018).

Передача коммуникативной инициативы может осуществляться также посредством

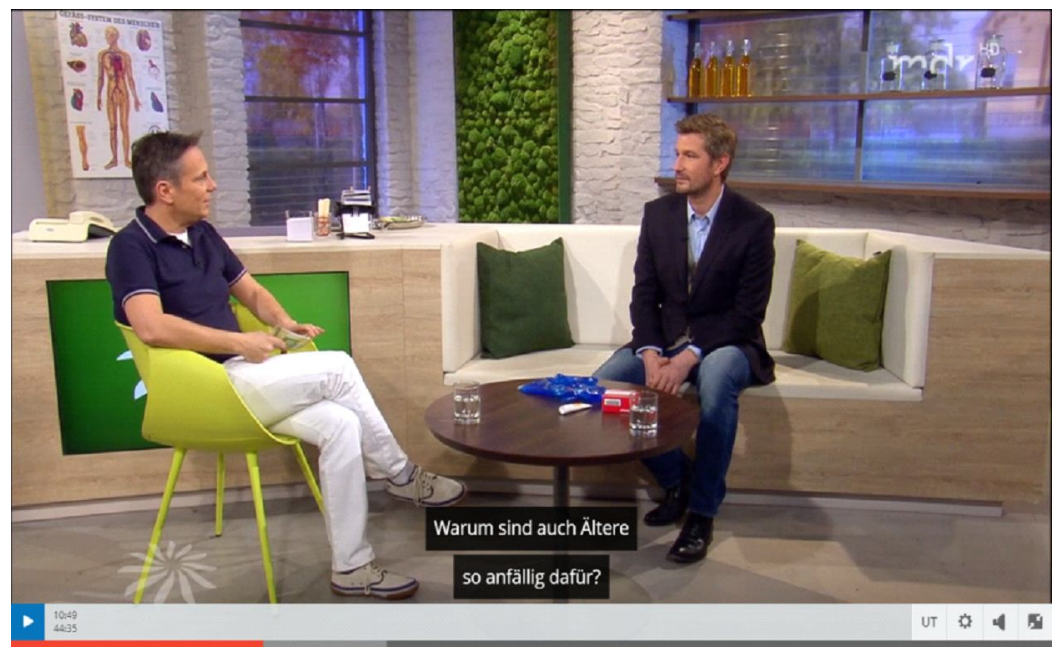

Рис. 1. Прямой взгляд адресанта на собеседника 
речевых формул: ...oder? ...nicht wahr? ...ja?, являющихся в немецком языке элементами «речевой организации» [Wunderlich, 1976, S. 331]:

(6) Ситуативный контекст: К.1 - ведущий, К.2-врач.

K.1: Das kann auch ein Gürtel vom Bademantel sein oder?

$$
\text { K.2: Ja (12.01.2017). }
$$

(7) Ситуативный контекст: К.1 - ведущий, К. 2 - эксперт ток-шоу.

K.1: Herzlich willkommen Nicole Lins, Ernährungsexpertin. Nicole, das klingt für manch einen vielleicht zu simpel: Wer viel Zucker isst, wird zuckerkrank oder?

K.2: Es ist aber tatsächlich so, wobei nicht nur Zucker alleine, sondern alle Kohlenhydrate. Der Zuckerspiegel geht hoch, wir brauchen Insulin. Dann muss immer mehr Insulin ausgeschüttet werden und dann hat man relative schnell den Diabetes (15.06.2017).

Призыв к высказыванию является ожидаемым в рамках рассматриваемой телепередачи, поэтому перераспределение инициативы осуществляется по взаимному согласию собеседников:

(8) Ситуативный контекст: К.1 - ведущий, К. 2 - врач.

K.1: Teilweise kann man auch andere Behandlungen machen. Wir haben mal einen Film vorbereitet. Sie können ja mal kurz erklären, was da passiert.
K.2: Wir sehen hier eine Katheter-Untersuchung. Hier wird ein kleiner Draht durch ein verstecktes Gefäss geschoben. Material wird abgesaugt. Blutgerinnsel, dass das Gefäss verstopft hat. Die Patienten sind örtlich betäubt. Im Verlauf kann man sehen, wie sich die Gefässe weiten (10.08.2017).

В приведенном примере призыв к высказыванию - вежливая и мягкая форма перераспределения ролей собеседников.

Анализ собранного фактического материала позволил обнаружить случай передачи коммуникативной инициативы, которая совершается посредством незаконченных предложений, то есть говорящий преднамеренно не заканчивает свою мысль. Кроме того, адресант изменяет интонацию, что также является призывом к ответу собеседника:

(9) Ситуативный контекст: К.1 - ведущий, К. 2 - врач.

K.1: Der Körper gewöhnt sich also an die hohen Insulinmengen. Wenn wir also zu reduzieren...

K.2: Oder noch weitergehen, die Kohlenhydrate im gesamten reduzieren, könnten wir den Diabetestyp 2 heilen (08.06.2017).

Необходимо обратить внимание на невербальный сигнал, используемый модератором, - жест, при котором указательный палец направлен в сторону слушающего (рис. 2).

Современные лингвисты относят данный невербальный сигнал к «дейктическим иллюстративным жестам», отмечая, что такой кинемой говорящий выражает адресованность

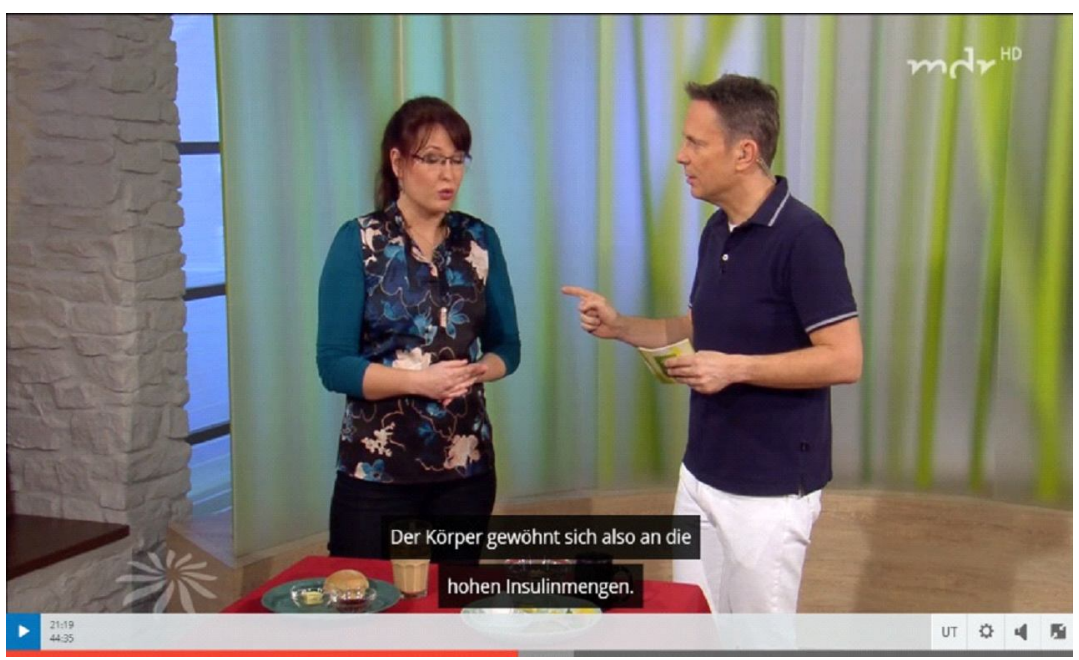

Рис. 2. Жест, при котором указательный палец направлен в сторону слушающего 
к собеседнику [Петрова, Егорченкова, Шамне, 2016, с. 103]. В примере (9) данный жест сигнализирует о том, что адресант ожидает ответа от адресата.

Как отмечает О.С. Иссерс, сохранение инициативы говорящим может происходить благодаря его собственным усилиям или усилиям собеседника [Иссерс, 2008, с. 221]. Формат рассматриваемой нами передачи не предполагает недружелюбного или невоспитанного поведения участников ток-шоу, поэтому частотной тактикой в проанализированном материале является тактика «поощрения инициативы», которая реализуется посредством усилий второго коммуниканта. Нами отмечены случаи использования вербальных сигналов, когда слушающий поощряет инициативу говорящего, прибегая к минимальным репликам: Ja-ja, natürlich, richtig, genau .

(10) Ситуативный контекст: К.1 - врач, К.2 ведущий.

K.1: Der Patient kann aktiv den Arm bewegen. Sonst bewegt man den Arm passiv und schaut, ab wann tut es weh. So kann man auch die Kraft testen. Z.b. bittet man den Patienten gegen zu spannen.

K.2: Ja-ja.

K.1: Man kann dann schauen, ob eine Sehne betroffen ist. Das sind die ersten Hinweise (17.08.2017).

(11) Ситуативный контекст: К.1 - врач, К.2 ведущий.

K.1: Die Schulterkapsel ist da entzündet. Es bleibt in der Regel nur die operative Möglichkeit. Man versucht die Narben zu lösen, auf zu denen. Gegebenenfalls sogar die Kapsel durhzuschneiden. Man guckt, wo sind noch Narbenstränge, die ich noch nicht gelöst habe. Die Schulter wird danach physiotherapeutisch behandelt.

K.2: Natürlich, ja.

K.1: Hier kann man die Schulter nur schwer bewegen. Hier ist eine intensive Entzündung des Schleimbeutel in der Schulter vorhanden (17.08.2017).

Анализ собранного фактического материала позволил выявить ситуации, в которых инициатива поощряется участниками ток-шоу с помощью невербального сигнала: кивком головы. Этот жест лингвисты относят к «жестам-регуляторам» диалога, которые могут сопровождать речь или использоваться отдельно от нее. Функция «жестов-регуляторов» диалога заключается в том, что они поддер- живают общение и способны управлять им [Петрова, Егорченкова, Шамне, 2016, с. 92]. Приведем пример такой ситуации, зафиксированный в нашем материале:

(12) Ситуативный контекст: К.1 - ведущий, К.2- врач.

K.1: Es gibt noch eine 3. Methode. Auch die ist relative neu: ein Magnetband. Was wird da gemacht?

K.2: Das Magnetband ist ein Band aus Titankugeln. Die haben einen Magnetkern. Der wird unter die untere Speiseröhre herumgeschlungen. Durch die Magnetkraft wird das Band wieder zusammengezogen. Es schützt auf der anderen Seite vor dem Rückfluss von Mageninhalt. Wenn der Druck gross ist, dann öffnet sich das Band. Wenn man erbricht, dann ffnet sich das Band auch. Wenn der Druck aber nur ein wenig steigt, wie beim Reflux, dann schützt das Band vor dem Zurücklaufen (08.03.2018).

Высказывание одного из участников диалога сопровождается кивком головы, который направлен на поддержание коммуникации, в данном случае на ее поощрение, так называемый сигнал одобрения продолжения разговора. В современной лингвистике такой жест называют «академическим кивком». Многократно повторяющийся, как в приведенной ситуации, данный сигнал является ярким выражением фатической функции [Егорченкова, Шамне, 2016, с. 114]. Одобрение слов говорящего инсценируется более активно, поскольку кивок головы сопровождается закрыванием глаз (см. рис. 3).

В рассматриваемом материале обнаружены случаи реализации тактики «взятия инициативы». Ее использует ведущий токшоу, когда высказывание партнера (врача или пациента) затянулось и не укладывается во временной лимит телепередачи.

(13) Ситуативный контекст: К.1 - врач, К.2 ведущий.

K.1: Ich habe versucht, dass er nicht losrennt. Ich habe festgehalten. Es hat auch nicht wirklich weh getan. Die Ärztin meinte dann, bitte gehen Sie dort nach drüben. Bitte benutzen Sie das Desinfektionsmittel. Bitte gehen Sie sofort zum Arzt.

K.2: Und es ist dick geworden! Wir haben Fotos...

K.1: Und es ist.

K.2: Hier haben wir ein Foto. Das ist die operierte Hand. Genäht sieht das so aus. Auch heute haben sie noch eine Narbe. Warum muss man beim Hundebiss so stark operieren? (07.09.2017). 
В приведенном примере ведущий токшоу берет инициативу и продолжает рассказ пациента о том, что его рука распухла после укуса собаки, а далее переключает внимание телезрителя с пациента на фотографии прооперированной руки. Кроме этого, ведущий ток-шоу использует невербальный сигнал (рис. 4) - кинесический жест особого привлечения внимания «указательный палец вверх» (подробно о таком жесте см.: [Петрова, Егорченкова, Шамне, 2016, с. 120]).

Проанализированный нами материал позволяет сделать вывод о том, что тактика «уклонения от инициативы» реализуется в коммуникативном взаимодействии ведущего и пациента, врача и пациента. По мнению O.C. Иссерс, одним из приемов уклонения от инициативы со стороны слушающего являют- ся однословные ответы, которые демонстрируют коммуникативную пассивность [Иссерс, 2008 , с. 222]. Приведем пример из нашего материала:

(14) Ситуативный контекст: К.1 - врач, К.2 пациент.

K.1: Was wir als nächstes machen, ist, dass wir ihre Hände in Eiswasser baden, so dass wir die Situation simulieren, die Ihnen immer so zu schaffen macht.

\section{K.2: Gut.}

K.1: Hier ist der Finger, der Ihnen gerade zu schaffen gemacht hat, wunderbar durchblutet.

K.2: Ok, verständlich.

K.1: Wir können an der Stelle sagen, dass keine Gefässe verstopft sind. So wie es aussieht, ist es ein Raynaud-Phänomen. Das können wir heute bestätigen. Das zeigt auch diese Untersuchung (20.04.2017).

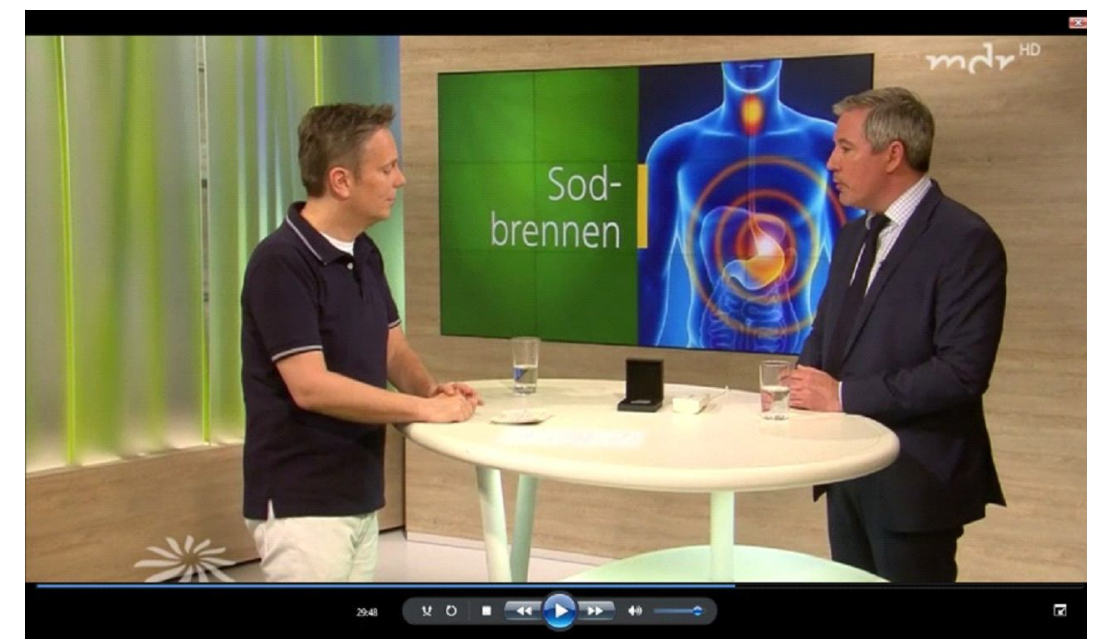

Рис. 3. Кивок головы с закрыванием глаз

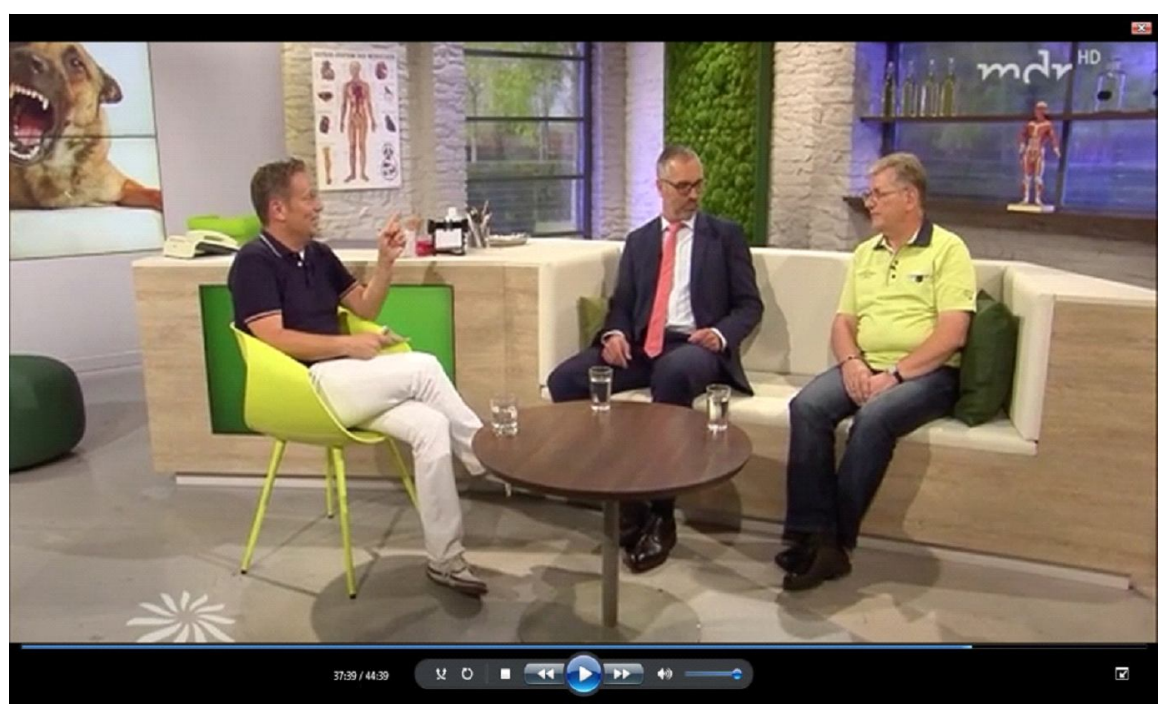

Рис. 4. Кинесический жест особого привлечения внимания «указательный палец вверх» 


\section{МАТЕРИАЛЫ И СООБЩЕНИЯ}

Мы считаем, что в приведенном примере слушающий (пациент) уклоняется от инициативы не потому, что не хочет поддерживать разговор, а потому, что не способен его поддерживать, поскольку является носителем не профессиональной, а наивной картины мира (о таких ситуациях подробнее см.: [Жура, 2012, с. 54]).

Особым случаем контроля над инициативой является тактика «завершения разговора». Существуют ситуации, когда беседа завершается по обоюдному желанию партнеров. Однако особенно сложным в плане реализации завершения разговора становится односторонний выход из диалога. Анализируя такие ситуации, О.С. Иссерс выделяет три коммуникативных приема, посредством которых совершается односторонний выход из коммуникации: прямой, косвенный и вспомогательный. К прямым приемам завершения разговора исследователь относит эксплицитные сообщения о завершении, более вежливые сообщения о намерении уйти и ритуальные завершения в рамках этикета, такие как, например, положительная оценка разбираемой проблемы и обобщение. К косвенным приемам завершения диалога автор относит уклонение от участия в беседе, сообщения, связанные с невозможностью развивать разговор вследствие временной ограниченности, присутствием третьего собеседника, состоянием здоровья и т. п., намеки на занятость участника речевого взаимодействия. К вспомогательным приемам завершения разговора О.С. Иссерс причисляет смену темы и переключение внимания на другого участника дискуссии [Иссерс, 2008, с. 226-227].

Коммуникация в рамках медицинского медийного дискурса направлена на передачу медицинской информации и ее правильное восприятие массовой аудиторией. Этические нормы данной дискуссии требуют взаимного уважения коммуникантов и эффективного общения. В проанализированном материале реализуются прямые, косвенные и вспомогательные тактики завершения дискуссии. Наиболее частотной является вспомогательная тактика завершения разговора, которая используется ведущим ток-шоу для того, чтобы вежливо закончить обсуждение одного аспекта проблемы и перейти к другому.
Изучая фактический материал, мы смогли выявить примеры реализации вспомогательной тактики завершения разговора:

(15) Ситуативный контекст: К.1 - врач, К.2 ведущий.

K.1: Der Sonnenstich kann auch gefährlich sein. Aber meistens ist er nicht gefährlich. Meistens ist er nur mit Kopfschmerzen und etwas Übelkeit verbunden. Manchmal auch mit Erbrechen.

K.2: Wenn jemand überhitzt ist, führen wir Kälte zu. Idealer Weise schützt man sich aber sowieso gegen die Hitze. Und wie machen die Menschen das? Schauen wir ins Tierreich. Wildschweine suhlen sich gerne im Schlamm. Vögel und Hunde Eicheln. Und Störhe beschweren sich mit Kot. Und der Mensch? (15.06.2017).

В приведенном фрагменте дискуссии врач высказывается на тему солнечного удаpa, а ведущий телепередачи использует невербальный сигнал, когда коммуникативная инициатива переходит в его руки (см. рис. 5).

Предвидя возможные действия собеседника (прерывание, вклинивание в разговор), ведущий ток-шоу вынужден реагировать на поведение партнера, поэтому использует жест-регулятор, представляющий собой виртуальную преграду, запретительный жест (рука поднята, ладонь направлена в сторону собеседника), нацеленный на предотвращение вклинивания (о таких знаках см.: [Егорченкова, Шамне, 2016, с. 113]). Кроме этого, ведущий изменяет тему разговора, и его фраза заканчивается вопросом, ответ на который телезритель находит уже в следующем сюжете ток-шоу. Таким образом, дискуссия между врачом и ведущим завершается.

Еще одним примером реализации вспомогательной тактики завершения разговора является переключение внимания на другого собеседника:

(16) Ситуативный контекст: К.1 - пациент, К.2 ведущий, К.3 - приглашенный эксперт.

K.1: Ich bin am Morgen ins Bad gegangen und musste niesen. Um die andere nicht aufzuwecken, habe ich mir Handtuch genommen. Und ich nieste hinein und klappte vor Schmerz zusammen wie ein Taschenmesser.

K.2: Dieser Druck unten auf den Kanal hat das ausgelöst. Was mache ich da? 


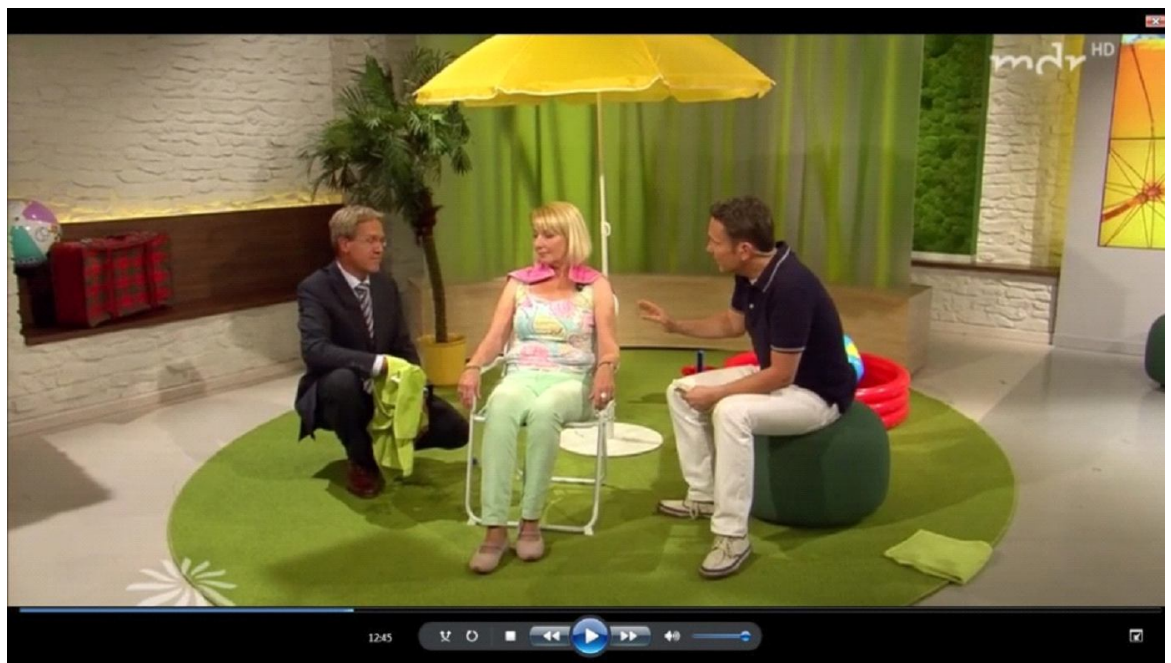

Рис. 5. Приподнятая рука направлена в сторону собеседника

K.3: In einer Weise sich auf die Erde legen oder ins Bett. Und die Beine hoch legen. Das nennt man Stufenlagerung. Das kann man schlecht vormachen, dass es bei jedem anders, wie er in diese Position kommt. Aber irgendwie muss auf dem Rücken liegen und die Beine sind oben (15.06.2017).

В данном примере после последней фразы пациента ведущий переключает свое внимание и внимание зрителей на приглашенного эксперта и задает ему вопрос, поскольку его интересует авторитетное мнение в рамках обсуждаемой проблемы. Кроме этого, ведущий ток-шоу использует вспомогательный невербальный сигнал (рис. 6), демонстрирующий вежливость, - указывает рукой в сторону «авторитета» (подробную характеристику этого жеста см. в работе: [Петрова, Егорченкова, Шамне, 2016, с. 104]).

После обращения ведущего к специалисту его диалог с пациентом завершается.

В рамках анализируемой телепередачи встречается косвенная тактика завершения беседы, которая, в большинстве случаев, связана с временной ограниченностью. Поскольку дискуссии телевизионного ток-шоу «вписаны» в строгие временные рамки, коммуникация собеседников строго регламентируется, а за соблюдением правил следит ведущий:

(17) Ситуативный контекст: К.1 - врач, К.2 ведущий.

K.1: Man sollte den Körper schützen vor Auskühlung. Der Körper versucht, dieses Wärme zu

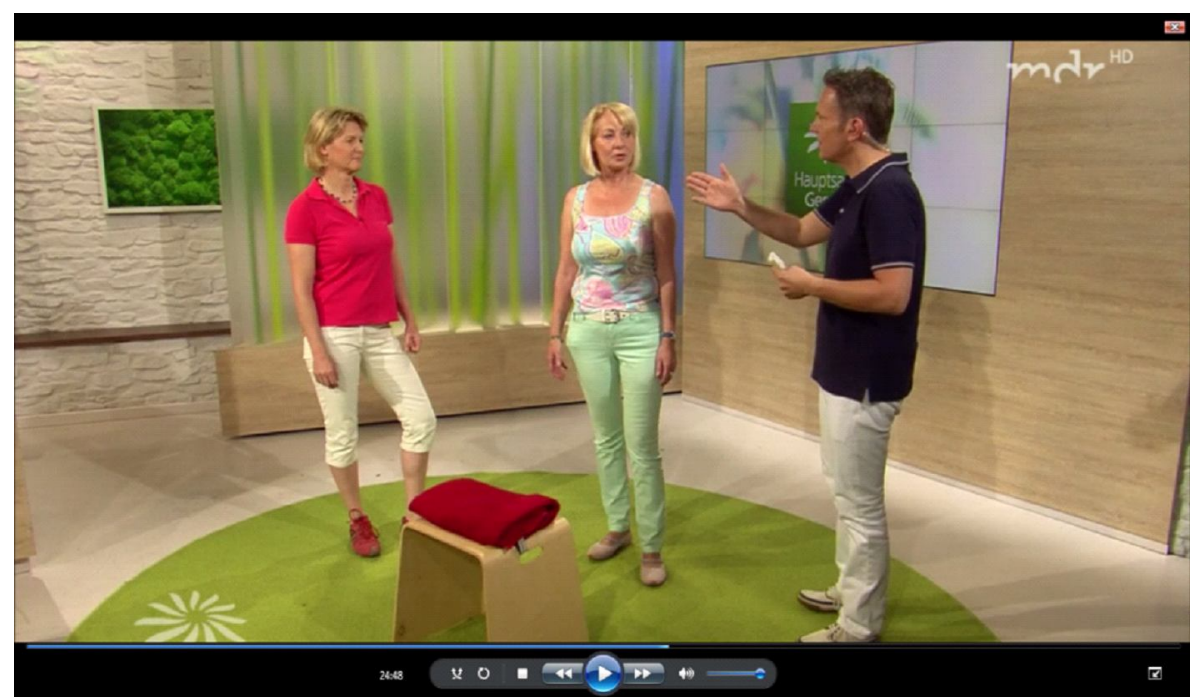

Рис. 6. Ведущий указывает рукой в сторону эксперта 


\section{МАТЕРИАЛЫ И СООБЩЕНИЯ}

zentralisieren. Verletzungen sind aber möglich, die schlecht abheilen. Oder Krankheiten, die zu Grunde liegen, dass man auskühlt. Das ist auf Basis von ätherischen Ölen. Damit kann man sich die Hände oder Füsse einreiben. Das fördert ein bisschen die Durchblutung. Das fördert die Feinmotorik. Es ist eine schöne Variante. Sie trainieren die Handmuskeln und regen die Gefässe an...

K.2: Und sie können Handschuhe und Socken stricken! genau!

K.1: Warme Socken und Handschuhe stricken,

K.2: Vielen Dank für das Gespräch, Frau Dr. Mühlberg (15.06.2017).

В приведенном примере ведущий перехватывает инициативу у врача, используя шутку, и переключает внимание телезрителя на себя, прощаясь с приглашенным экспертом.

В медицинском медийном дискурсе встречается прямая тактика завершения дискуссии. Однако отметим, что коммуникативные приемы, которые прямо указывают на завершение речевого взаимодействия, такие как эксплицитные сообщения, неприемлемы в рамках анализируемого ток-шоу о здоровье. Выше мы упоминали о том, что существуют более вежливые ритуальные завершения в рамках этикета, которые являются актуальными в рассматриваемой телевизионной передаче:

(18) Ситуативный контекст: К.1 - приглашенный эксперт, К.2 - ведущий.

K.1: Ja richtig, wir geben der Bandscheibe die Chance, wieder rein zu gehen.

K.2: Bett und Schulleitung sind komplett tabu. Den Ruhe kann die Symptome zusätzlich verschlimmern. Wie so oft hilft wie so oft nur Bewegung. Aber dazu müssen erstmal die Schmerzen weg und dabei hilft die Schmerztherapie(15.06.2017).

В приведенном фрагменте финальная реплика используется для реализации прямой тактики завершения разговора, которая представлена подведением итогов, то есть резюмированием.

\section{Выводы}

В медицинском медийном дискурсе мена коммуникативных ролей осуществляется в стратегии «контроля коммуникативной инициативы», для реализации которой используют- ся разные тактики в зависимости от статуса коммуникантов. Частотна тактика «передачи инициативы», которая актуализируется усилиями ведущего ток-шоу, поскольку он является модератором: следит за развитием действия и подготавливает телезрителя к очередному сюжету. Адресаты, как правило, обращаются к тактике «взятия инициативы». Сохранение коммуникативной инициативы осуществляется посредством тактики «поощрения инициативы», используемой слушающим. Тактика «уклонения от инициативы» реализуется пациентами вследствие того, что они, будучи носителями наивной картины мира, не способны поддерживать профессиональную дискуссию. Прямые, косвенные и вспомогательные тактики «завершения разговора» в полной мере используются ведущим ток-шоу. Наиболее частотна вспомогательная тактика «завершения разговора», реализуемая посредством смены темы и переключения внимания на другого собеседника. При воплощении стратегии контроля коммуникативной инициативы участниками ток-шоу применяются и невербальные сигналы, сопровождающие высказывание и актуализирующие ту или иную тактику.

\section{ПРИМЕЧАНИЕ}

${ }^{1}$ Использованы материалы ток-шоу «Hauptsache Gesund», представленные на сайтах Mitteldeutsche Rundfunk (https://www.mdr.de) и ARD (www.ardmediathek.de). В ссылках на выпуски токшоу указана дата выпуска.

\section{СПИСОК ЛИТЕРАТУРЫ}

Арутюнова Н. Д., 1990. Феномен второй реплики, или О пользе спора // Логический анализ языка. Противоречивость и аномальность текста / отв. ред. Н. Д. Арутюнова. М. : Наука. С. 175-189.

Дейк Т. А. ван, Кинч В., 1988. Стратегии понимания связного текста // Новое в зарубежной лингвистике. Когнитивные аспекты языка / сост., ред. и вступ. ст. В. В. Петрова, В. И. Герасимова. М. : Прогресс. Вып. 23. С. 153-211.

Демьянков В. 3., 1983. Аргументирующий дискурс в общении // Речевое общение: проблемы и перспективы : сб. науч.-аналит. обзоров / сост. В. Г. Садур. М. : ИНИОН. С. 114-131. 
Егорченкова Н. Б., Шамне Н. Л., 2016. Координативные ресурсы мультимодальной интеракции в политическом ток-шоу // Вестник Волгоградского государственного университета. Серия 2, Языкознание. № 1 (30). С. 107-118. DOI: https://doi.org/10.15688/jvolsu2.2016.1.14.

Жура В. В., 2012. Взаимодействие картин мира врача и пациента в ходе медицинской коммуникации и способы их экспликации // Общество ремиссии: на пути к нарративной медицине : сб. ст. / под общ. ред. В. Л. Лехциера. Самара : Изд-во Сам. гос. ун-та. С. 54-65.

Ильина И. А., Покидов Д. К., 2017. Дискурс-анализ общественно-политических ток-шоу // Ученые записки Санкт-Петербургского университета технологий управления и экономики. № 2 (58). С. 62-74.

Иссерс О. С., 2008. Коммуникативные стратегии и тактики русской речи. 5-е изд. М. : ЛКИ. 288 с.

Клюев Е. В., 2002. Речевая коммуникация: успешность речевого взаимодействия. М. : Рипол Классик. 320 с.

Кудрявцева А. Ю., 2017. Речевые реализации стратегии доминирования в официальном полилоге (на материале ток-шоу) : дис. ... канд. филол. наук. СПб. 184 с.

Лукашова Р. Н., 2014. К вопросу о коммуникативных стратегиях и тактиках // Лингвистика и межкультурная коммуникация в современном мире : материалы VII Науч.-практ. конф. с междунар. участием / отв. ред. Л. Р. Татарникова. Чита : Изд-во Забайк. гос. ун-та. С. 23-29.

Макаров М. Л., 2003. Основы теории дискурса. М. : Гнозис. 280 с.

Невзорова М. С., 2017. Стратегия тематического контроля медицинской научно-профессиональной дискуссии // Филологические науки. Вопросы теории и практики. № 7 (73), ч. 1. С. 135-140.

Петрова А. А., Егорченкова Н. Б., Шамне Н. Л., 2016. Мультимодальное взаимодействие в интерактивном пространстве медиа-политического дискурса : монография. Волгоград : Волгогр. науч. изд-во. $144 \mathrm{c}$.

Сухих С. А., 1986. Речевые интеракции и стратегии // Языковое общение и его единицы : межвуз. сб. науч. тр. / собр., ред., предисл. И. П. Сусов. Калинин : Изд-во КГУ. С. 71-77.

Яшина Н. В., 2014. Некоторые особенности организации речевого взаимодействия в телеинтервью // Человек в информационном пространстве : сб. науч. тр. / под общ. ред. Н. В. Аниськиной. Ярославль : Изд-во Яросл. гос. пед. унта им. К.Д. Ушинского. С. 213-218.

Parret H., 1983. Semiotics and Pragmatics : An Evaluative Comparison of Conceptual Frameworks. Amsterdam : Philadelphia. 136 p.
Sacks H., 1992. Lectures on Conversation / ed. G. Jefferson. USA : Blackwell Publishing. 2 vols.

Wunderlich D., 1976. Studien zur Sprechakttheorie. Frankfurt a. M. : Suhrkamp. 416 S.

\section{REFERENCES}

Arutyunova N.D., 1990. Fenomen vtoroy repliki ili o polze spora [Phenomenon of the Second Remark or About Advantage of a Dispute]. Logicheskiy analiz yazyka. Protivorechivost $i$ anomalnost teksta [The Contradictory and Anomalous Character of the Text]. Moscow, Nauka Publ., pp. 175-189.

Deyk T.A. van., Kinch V., 1998 Strategii ponimaniya svyaznogo teksta [Strategies for Understanding of Coherent Text]. Petrova V.V., Gerasimova V.I., eds. Novoe v zarubezhnoy lingvistike. Kognitivnye aspekty yazyka [New Tendensies in Foreign Linguistics. Cognitive Aspects of Language], no. 23, pp. 153-211.

Demyankov V.Z., 1983. Argumentiruyushchiy diskurs $\mathrm{v}$ obshchenii [The Reasoning Discourse in Communication]. Sadur V.G., ed. Rechevoe obshchenie: problemy i perspektivy: sb. nauch.analit. obzorov [Speech Communication: Problems and Prospects: Collection of Scientific and Analytical Reviews]. Moscow, INION Publ., pp. 114-131.

Egorchenkova N.B., Shamne N.L., 2016. Koordinativnye resursy multimodalnoy interaktsii v politicheskom tok-shou [Coordinative Resources of Multimodal Interaction in Political Talk-Show]. Vestnik Volgogradskogo gosudarstvennogo universiteta. Seriya 2, Yazykoznanie [Science Journal of Volgograd State University. Linguistics], no. 1 (30), pp. 107-118. DOI: http://dx.doi.org/10.15688/ jvolsu2.2016.1.14.

Zhura V.V., 2012. Vzaimodeystvie kartin mira vracha i patsienta v khode meditsinskoy kommunikatsii i sposoby ikh eksplikatsii [Interaction of Worldviews of Doctor and Patient During Medical Communication and Ways of Their Explication]. Lekhtsier V.L., ed. Obshchestvo remissii: na puti $k$ narrativnoy meditsine: sb. st. [Society of Remission: On the Way to Narrative Medicine. Collected Articles]. Samara, Izd-vo Samarskogo gosudarstvennogo universiteta, pp. 54-65.

Ilyina I.A., Pokidov D.K., 2017. Diskurs-analiz obshchestvenno-politicheskikh tok-shou [Discourse Analysis of Social and Political TalkShows]. Uchenye zapiski Sankt-Peterburgskogo universiteta tekhnologiy upravleniya $i$ ekonomiki [Scientific Notes of UMTE], no. 2 (58), pp. 62-74. 


\section{МАТЕРИАЛЫ И СООБЩЕНИЯ}

Issers O.S., 2008. Kommunikativnye strategii i taktiki russkoy rechi [Communicative Strategies and Tactics of the Russian Speech]. Moscow, LKI Publ. 288 p.

Klyuev E.V., 2002. Rechevaya kommunikatsiya: uspeshnost rechevogo vzaimodeystviya [Speech Communication: Success of Speech Interaction]. Moscow, Ripol Klassic Publ. 320 p.

Kudryavtseva A.Yu., 2017. Rechevye realizatsii strategii dominirovaniya $v$ ofitsialnom poliloge (na materiale tok-shou): dis. ... kand. filol. nauk [Speech Implementation of the Domination Strategy in the Official Polylogue (Based on Talk Shows). Cand. philol. sci. diss.]. Saint Petersburg. 184 p.

Lukashova R.N., 2014. K voprosu o kommunikativnykh strategiyakh i taktikakh [To the Issue of Communicative Strategies and Tactics]. Tatarnikova L.R., ed. Lingvistika i mezhkulturnaya kommunikatsiya v sovremennom mire: materialy 7-y Nauchno-praktich. konf. s mezhdunar. Uchastiem [Linguistics and Intercultural Communication in the Modern World. Proceedings of the $7^{\text {th }}$ Scientific and Practical Conference with the International Participation]. Chita, Izd-vo Zabaykalskogo gosudarstvennogo universiteta, pp. 23-29.

Makarov M.L., 2003. Osnovy teorii diskursa [Bases of the Discourse Theory]. Moscow, Gnozis Publ. $280 \mathrm{p}$.

Nevzorova M.S., 2017. Strategiya tematicheskogo kontrolya meditsinskoy nauchno-professionalnoy diskussii [Strategy of Thematic Monitoring of
Medical Scientific and Professional Discussion]. Filologicheskie nauki. Voprosy teorii i praktiki [Philological Sciences. Issues of Theory and Practice], no. 7 (73), part 1, pp. 135-140.

Petrova A.A., Egorchenkova N.B., Shamne N.L., 2016. Multimodalnoe vzaimodeystvie $v$ interaktivnom prostranstve media-politicheskogo diskursa: monografiya [Multimodal Interaction in Interactive Space of a Media and Political Discourse. Monograph]. Volgograd, Volgogradskoe nauchnoe izdatelstvo. $144 \mathrm{p}$.

Sukhikh S.A., 1986. Rechevye interaktsii i strategii [Speech Interactions and Strategies]. Yazykovoe obshchenie i ego edinitsy: mezhvuz. sb. nauch. tr. [Language Communication and Its Units. Interuniversity Collection of Scientific Papers]. Kalinin, Izd-vo KGU, pp. 71-77.

Yashina N.V., 2014. Nekotorye osobennosti organizatsii rechevogo vzaimodeystviya $v$ teleintervyu [Some Peculiarities of Organization of Speech Interaction in TV Interviews]. Aniskina N.V., ed. Chelovek v informatsionnom prostranstve: sb. nauch. tr. [Man in the Information Space. Collection of Scientific Papers]. Yaroslavl, Izd-vo Yaroslavskogo gosudarstvennogo pedagogicheskogo universiteta im. K.D. Ushinskogo, pp. 213-218.

Parret H., 1983. Semiotics and Pragmatics: An Evaluative Comparison of Conceptual Frameworks. Amsterdam, Philadelphia. 136 p.

Sacks H., 1992. Lectures on Conversation. USA, Blackwell Publ. 2 Vols.

Wunderlich D., 1976. Studien zur Sprechakttheorie. Frankfurt am Main, Suhrkamp. 416 s.

\section{Information about the Author}

Elena Yu. Vasil'eva, Postgraduate Student, Department of German and Romance Philology, Volgograd State University, Prosp. Universitetsky, 100, 400062 Volgograd, Russia, alyn85@mail.ru, https://orcid.org/0000-0002-6586-7209

\section{Информация об авторе}

Елена Юрьевна Васильева, аспирант кафедры германской и романской филологии, Волгоградский государственный университет, просп. Университетский, 100, 400062 г. Волгоград, Россия, alyn85@mail.ru, https://orcid.org/0000-0002-6586-7209 